\title{
Pelletization of Refuse-Derived Fuel with Varying Compositions of Plastic, Paper, Organic and Wood
}

\author{
Hamid Rezaei ${ }^{1, * \mathbb{C}}$, Fahimeh Yazdan Panah ${ }^{1}$, C. Jim Lim ${ }^{1}$ and Shahab Sokhansanj ${ }^{1,2}$ \\ 1 Chemical and Biological Engineering Department, University of British Columbia, Vancouver, BC V6T 1Z3, \\ Canada; fahimeh.yazdanpanah@ubc.ca (F.Y.P.); jim.lim@ubc.ca (C.J.L.); shahab.sokhansanj@ubc.ca (S.S.) \\ 2 Chemical and Biological Engineering Department, University of Saskatchewan, Saskatoon, SK 3B48, Canada \\ * Correspondence: hamid.rezaei@ubc.ca
}

Received: 26 May 2020; Accepted: 4 June 2020; Published: 6 June 2020

\begin{abstract}
The combustible fraction of municipal solid waste (MSW) is called refuse-derived fuel (RDF). RDF is a blend of heterogeneous materials and thus its handling is challenging. Pelletization is an efficient treatment to minimize the heterogeneity. In this research, typical RDF compositions were prepared by mixing several mass fractions of paper, plastic, household organic and wood. The collected compositions were ground, wetted to $20 \%$ moisture content (wet basis) and pelletized. Increasing the plastic content from $20 \%$ to $40 \%$ reduced the pelletization energy but increased the pellet's calorific value. Pellets with higher plastic content generated more dust when exposed to shaking. Making durable pellets with $40 \%$ plastic content needed an increase in die temperature from $80^{\circ} \mathrm{C}$ to $100{ }^{\circ} \mathrm{C}$. Increasing the paper content from $30 \%$ to $50 \%$ increased the durability but consumed higher energy to form pellets. Paper particles increased the friction between pellet's surface and die wall as was evident from expulsion energy. Force versus displacement curve for material compression revealed that the RDF compositions have rigid material characteristics.
\end{abstract}

Keywords: municipal solid waste (MSW); refuse-derived fuel (RDF); pelletization; composition; pellet durability

\section{Introduction}

Municipal solid waste (MSW) management is becoming complicated by the exponential growth of the global population [1]. Although recycling technologies are getting more advanced, a significant portion of MSW still ends up in landfills [2]. Burying waste in landfills leaches the toxins into the soil and water, and emits greenhouse gases like methane and carbon dioxide [3,4]. Landfilling is a big loss of resources such as material, energy and the valuable land used up for landfill sites $[5,6]$. A substantial reduction in landfilling is the ultimate goal of efficient waste management [2,7-9].

MSW consists of three major fractions of combustible, non-combustible and moisture or evaporative material $[10,11]$. The combustibles that are called "refuse-derived fuel (RDF)" are separated in sorting facilities [10,12,13]. RDF is combusted individually or co-fired in the cement kilns [14-16], steel furnaces, power stations [17], or incinerated in energy-from-waste plants $[5,18,19]$. The heterogeneous physical properties create problems during material flow [20]. For instance, the industrial pneumatic flow of RDF is not feasible, because the RDF components have different density values. Airflow carries the light plastic and papers and the heavy components remain in feeding lines [20]. Making the pellet form of solid waste reduces the variability in size, moisture and density. Using pellet form of feedstock facilitates the handling and flowability of material [21-24].

Densification data for cellulosic biomass pelletizing is available [25-27], but these data do not apply to RDF pelletization. Sprenger et al. [28,29] investigated the pellet density of an RDF composition with fractions of $35 \%$ paper, $22 \%$ plastics, $14 \%$ fabrics, $6 \%$ organics/woods and $23 \%$ fines. The nature or 
source of fines was not revealed. Sprenger et al. did not investigate variations in RDF composition. In the previous study, Rezaei et al. [30] densified an RDF with $20 \%$ plastic, $50 \%$ mixture of paper and cardboard, $20 \%$ food residue organics and 10\% wood. They concluded that for this specific composition a knife mill equipped with a 4 -mm screen wetted to $20 \%$ moisture content produced the most durable pellets with the minimum energy intake [30].

RDF composition varies with season, location of waste collection and efficiency of MSW sorting. Reviewing the data from sorting facilities showed that four major fractions of 15-35\% plastic, 15-50\% cellulosic paper and cardboard, 2-10\% wood, 5-20\% organics and about 5-10\% non-combustibles present in a typical RDF [4,15,31]. The United States Environmental Protection Agency, EPA (2012) [32] also reported a similar range of RDF composition. The collected data from material recovery facilities revealed that the RDF composition varies from batch to batch, too. Bessi et al. [31] classified the processed and sorted an MSW stream with a composition of 35\% paper, $24 \%$ plastic, $10 \%$ organics and $5 \%$ wood. The rest was textiles and some other inert materials. Casado et al. [4] investigated the RDF samples produced from a different MSW sorting stream and reported an average composition of $\sim 20 \%$ combination of hard and soft plastics, $48.5 \%$ paper, $15 \%$ mixture of wood and textile, $15.3 \%$ organic matter and the rest was non-combustibles. Fyffe et al. [15] used a waste stream with the composition of $25 \%$ plastics, $45 \%$ paper, $17 \%$ organics and $6 \%$ wood as an alternative solid fuel in cement kilns. None of these blends were pelletized. We concluded that a range of $20 \%$ to $40 \%$ plastic, $30 \%$ to $50 \%$ paper, $10 \%$ to $20 \%$ organic, and $10 \%$ wood are typical ranges of reported compositions.

The literature review revealed that the densification of RDF is still an unrecognized topic. There is a lack of experimental data and optimization for pelletization of RDF. The current research analyses the densification behavior of prepared waste compositions with variation in fractions of plastic, paper and organics in the blend. The percent of wood was kept fixed at $10 \%$. The analysis included force versus deformation data taken during RDF compaction and pellets expulsion from the die. The durability of pellets is analyzed and reported. A successful RDF pelletization is a promising approach to convert the solid waste into a standard solid fuel.

\section{Material and Methods}

\subsection{Preparation of RDF Compositions}

Batches of RDF were prepared by mixing four components of plastics, paper, organics, and wood (Figure 1). Rezaei et al. [30] described the details and specifications of the collected fractions. The collected plastic fraction was a combination of hard plastics cut from milk and juice containers and pieces of plastic film. Plastics were cut into $80-100 \mathrm{~mm}$ pieces using a scissor. Paper waste was collected from office scrap papers. Papers were inspected visually to ensure no ink and plastic film layer. Cardboard pieces were cut from a packaging grocery box. Papers and cardboards were manually ripped to 50-120 $\mathrm{mm}$ pieces. Organic fraction was collected from the organic waste bin of several households over 7 days. The fraction consisted of mostly the food residue ranging in size from 1-mm ground coffee particles up to the size of whole fruit like apple, orange or tomato. Large food items were cut into small pieces using a knife. Collected wood was shredded pine wood chips 5-20 mm in length.

The materials were individually dried in an oven (THELCO laboratory PRECISION oven, Thermo Electron Corporation, Model 6550, USA) at $50{ }^{\circ} \mathrm{C}$ over a 24-h period. Table 1 lists the as-received moisture content and dry-basis calorific value of individual fractions. Each component was ground individually using a knife mill (Retsch, model: SM 100) installed with a 4-mm diagonal dimension perforations screen. 


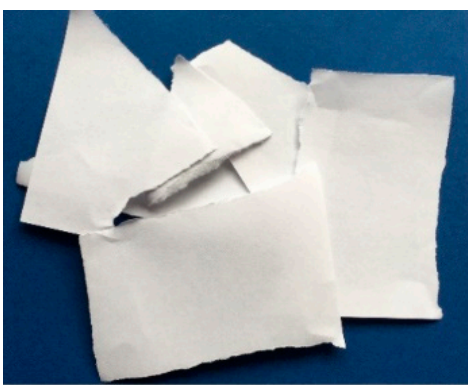

Paper

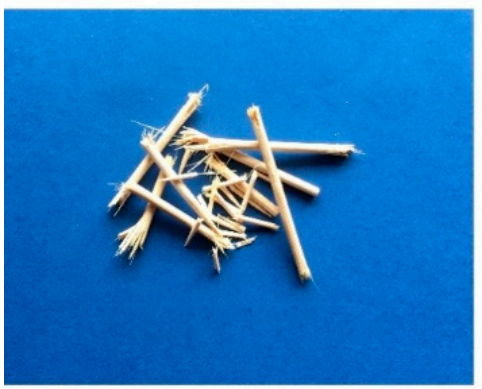

Wood

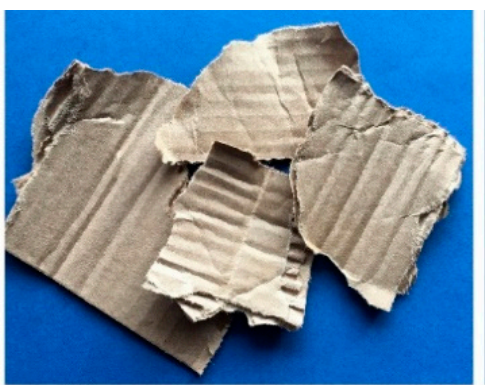

Cardboard

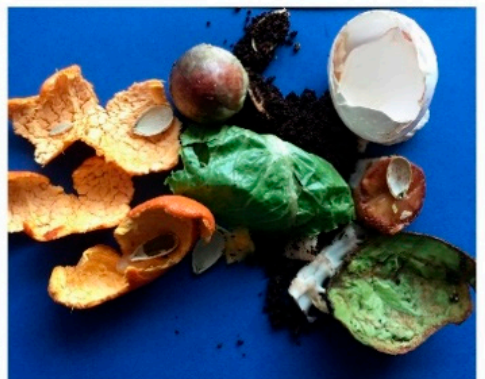

Organic

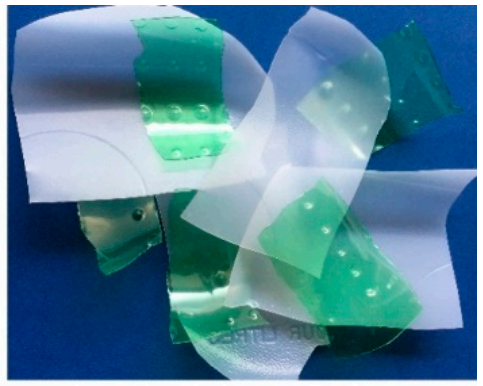

Hard plastic

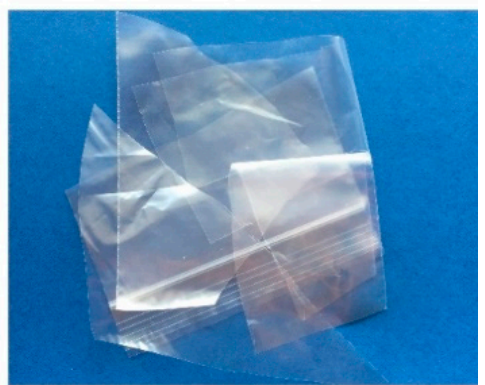

Soft plastic

Figure 1. Picture of the collected fractions. These wastes were dried, ground and blended to prepare the RDF samples.

The ground materials were mixed with four fractions listed in Table 1. Each blend was moistened to $20.0 \% \pm 0.5 \%$ (wet basis) by spraying water while rotating and agitating the material. The moistened blends were each sealed in a glass jar and stored at room temperature for $48 \mathrm{~h}$. The glass jar was intermittently rotated for uniform wetting. Moisture content of samples were measured after $48 \mathrm{~h}$ using a moisture analyzer (AND, model: MF-50, a precision of $0.05 \%$ ).

Table 1. As-received moisture content, dry basis calorific value and bulk density of individual components and prepared refuse-derived fuel (RDF) compositions at four fractions.

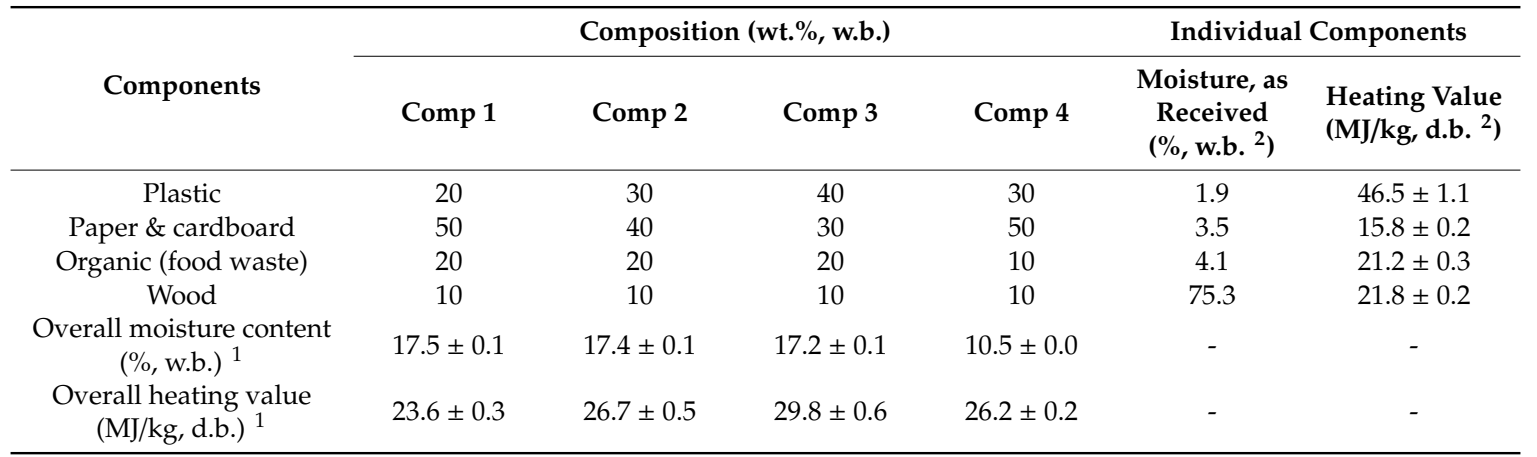

${ }^{1}$ Overall moisture content (\%, w.b.) and overall heating value (MJ $/ \mathrm{kg}$, d.b.) were calculated using a linear relationship with the individual moisture content and heating values. ${ }^{2}$ w.b. represents the wet basis and d.b. represents the dry basis.

\subsection{Particle Size, Bulk Density, and Calorific Value}

The ANSI/ASAE S319.4 Standard outlined the procedure to analyze particle size distribution. Mesh sieves of $0.25,0.5,1.0,1.4,2.0,3.35$ and $4.0 \mathrm{~mm}$ were stacked in a tap sieve shaker (Ro-Tap RX 94) with a 10-min roto-tap, shaking and tapping process. The mass retained on each sieve was measured to two decimal gram precision. Bulk density was measured by following the ASTM E1109-86 Standard. A constant mass of each sample was gently poured into a graduated cylinder. The volume of loose 
compositions was recorded. The ratio of measured mass to recorded volume was noted as the bulk density. Heating value was measured by the procedures outlined in ASTM D5865-13 Standard. The measurement was conducted using a bomb calorimeter (Parr Calorimeter, model 6100, USA). Approximately, $0.50 \mathrm{~g}$ of each waste fraction was initially oven dried. Dried samples were prepared to burn using an electrical wire passing through each sample in an oxygen bomb vessel. The produced heat of combustion was adsorbed by the water jacket. The calorific value of samples was calculated using the temperature rise in the water jacket. Rezaei et al. [22,33,34] explained the procedure for measurement of particle size distribution, bulk density and calorific value.

\subsection{Pelletization}

Pellets were made using a universal testing instrument (Measurements Technology Inc., Universal Testing Machine, Model MTI-50K). Figure 2 shows the stages of pelletization in the single pellet die. The single pellet unit was made up of a cylindrical die and piston assembly. A piece of removable solid steel block placed under the lower end of the cylinder. The block could be removed after making a pellet to allow the pellet exit from the bottom of the cylinder. A controlled electrical heat tape was wrapped around the die. Before each test, the die was heated to either 80 or $100^{\circ} \mathrm{C}$. The purpose of this study was not to investigate the influence of die temperature. All RDF compositions were densified at $80^{\circ} \mathrm{C}$. The sample with the highest plastic content (composition 3) was also densified at $100^{\circ} \mathrm{C}$. The cylinder-piston assembly with the removable block was placed under the moving head of the MTI. About $0.42 \pm 0.01 \mathrm{~g}$ of each blend was inserted inside the cylinder. The MTI piston was programmed to travel downward at a rate of $6 \mathrm{~mm} / \mathrm{min}$ for compression. The maximum force was set at $5000 \mathrm{~N}$. With respect to the $6.35 \mathrm{~mm}$ die internal diameter, the maximum applied pressure was $\sim 158 \mathrm{MPa}$. After reaching the maximum force, the formed pellet rested into the die for $30 \mathrm{~s}$. The steel block was removed and allowed the downward piston movement at a rate of $15 \mathrm{~mm} / \mathrm{min}$ to push the pellets out of the cylinder. Table 2 lists the operational parameters for pelletization. A batch of 10 pellets was produced and stored in individual glass vials for further analysis.
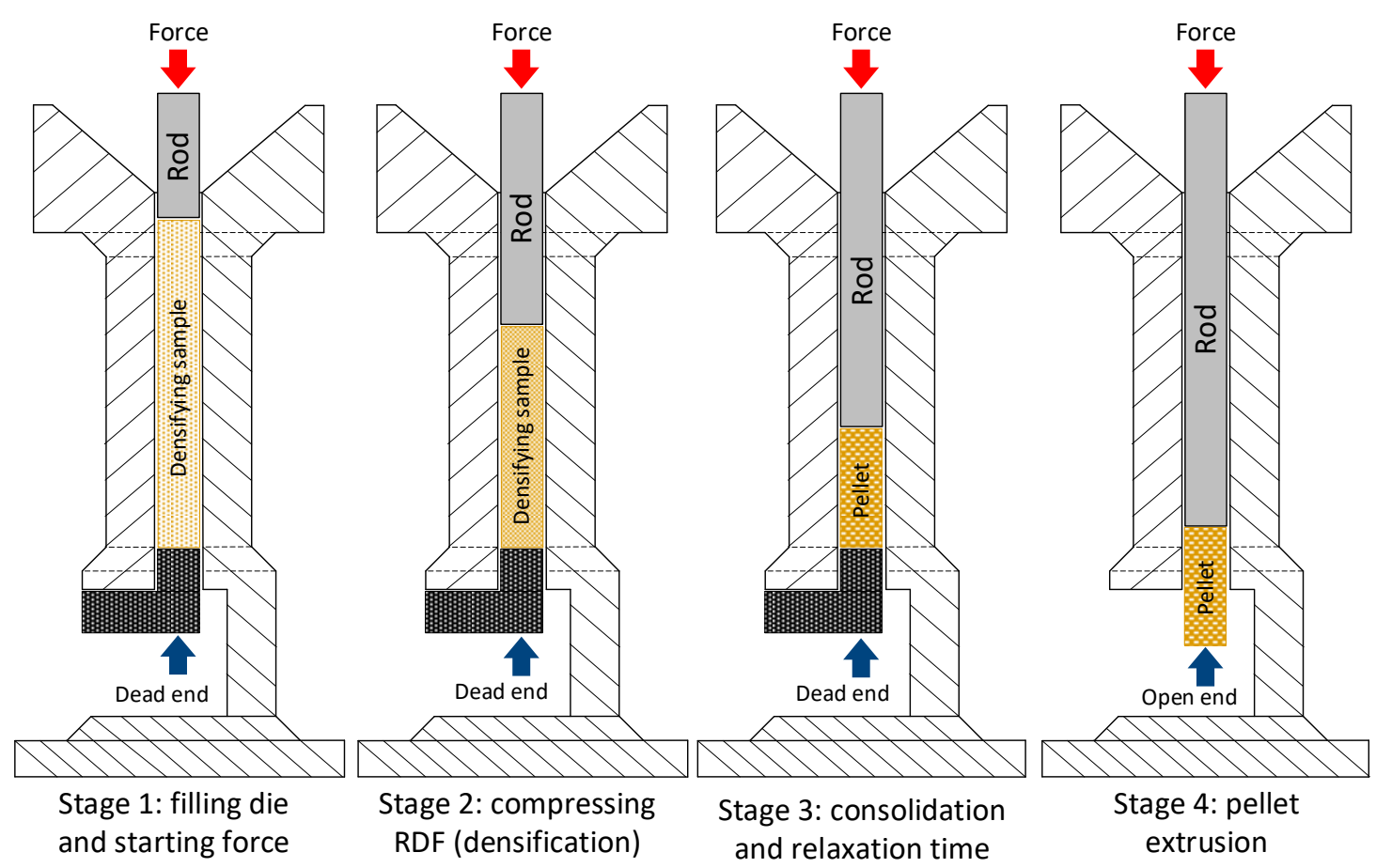

Figure 2. Schematic of the pelletization stages. The darker color of RDF sample into the die represents a higher density. 
Table 2. Operating parameters used in the single pellet machine.

\begin{tabular}{cc}
\hline Parameter & Value \\
\hline Die internal diameter & $6.35 \mathrm{~mm}$ \\
Maximum applied force & $5000 \mathrm{~N}$ \\
Maximum applied pressure & $158 \mathrm{MPa}$ \\
Die temperature & $80 \mathrm{and} 100{ }^{\circ} \mathrm{C}$ \\
Compression rate & $6 \mathrm{~mm} / \mathrm{min}$ \\
Expulsion rate & $15 \mathrm{~mm} / \mathrm{min}$ \\
Relaxation time & $30 \mathrm{~s}$ \\
Sample loading & $0.42 \pm 0.01 \mathrm{~g}$ \\
\hline
\end{tabular}

The software of pellet press recorded the force versus displacement. Rezaei et al. [30] and Nielsen et al. [35] described the analysis of force versus deformation data to characterize a pelletization process. The consumed energy was calculated from the numerical integration of force versus displacement data.

\subsection{Pellet Durability}

A single pellet durability analyzer was used to measure single pellet durability. This apparatus was developed to measure the durability of a small amount of pellet samples. The details of the developed technique were described by Schilling et al. [36]. This machine consisted of a cubic container with an inner dimension of $60 \mathrm{~mm} \times 60 \mathrm{~mm} \times 60 \mathrm{~mm}$, attached to the arm of a wrist action shaker (BURREL shaker, Model 75). A weighed single pellet along with a steel pellet (diameter of $6.3 \mathrm{~mm}$ and $24 \mathrm{~mm}$ long) were placed in the container. After shaking the container for $10 \mathrm{~min}$, its contents were sieved ( $3.15 \mathrm{~mm}$ opening size) and the generated broken particles and dust were separated. The remaining mass on the sieve was weighed in $\mathrm{mg}$ to one decimal precision. The durability was calculated as the ratio of mass on the sieve over the original mass of the pellet (EN 15210-1 Standard).

\section{Results and Discussion}

\subsection{Ground Composition Characterization}

Figure 3 shows the particle size distribution (PSD) of the blended RDF with four compositions. The opening size of the grinder screen was $4 \mathrm{~mm}$; almost the entire ground compositions had particles smaller than $2 \mathrm{~mm}$. Grinding paper generated larger particles than grinding other components. Larger paper content shifted the PSD to the larger particles. The peak of the PSD bar graph for composition 1 with $50 \%$ paper and $20 \%$ plastic was $~ 1.5-2.0 \mathrm{~mm}$. The peak for composition 3 with $30 \%$ paper and $40 \%$ plastic was $\sim 1 \mathrm{~mm}$. Paper particles made a fluffy bulk and had a high tendency to interlock, interfering with the free flowing of the material. Table 3 lists the bulk density of RDF compositions. Increasing the paper content reduced the bulk density, increasing plastic content increased bulk density.

Table 3. Density of samples before and after compression and the densification ratio of each composition. This table shows the variation of sample density before and after the compaction process at a die temperature of $80^{\circ} \mathrm{C}$.

\begin{tabular}{ccccc}
\hline Parameter & \multicolumn{4}{c}{ Composition } \\
\cline { 2 - 5 } & Comp 1 & Comp 2 & Comp 3 & Comp 4 \\
\hline Mass of RDF fed to die $(\mathrm{g})$ & $0.42 \pm 0.01$ & $0.42 \pm 0.01$ & $0.42 \pm 0.01$ & $0.42 \pm 0.01$ \\
Density before pelletization $\left(\mathrm{kg} / \mathrm{m}^{3}\right)$ & $108.1 \pm 3.2$ & $133.3 \pm 4.1$ & $160.0 \pm 2.8$ & $117.6 \pm 3.6$ \\
Densification factor & 10.6 & 8.1 & 6.5 & 10.2 \\
Density of pellet $\left(\mathrm{kg} / \mathrm{m}^{3}\right)$ & $1145.8 \pm 30.1$ & $1079.7 \pm 33.2$ & $1040.0 \pm 18.2$ & $1199.5 \pm 36.7$ \\
\hline
\end{tabular}

The heating value of plastic at $46.55 \mathrm{MJ} / \mathrm{kg}$ was three times the heating value of paper at $15.8 \mathrm{MJ} / \mathrm{kg}$ (Table 1). The presence of high-density polymers with long carbon chains [37] contributes to high 
heating value. Dry organic and dry wood fractions have a similar heating value at around $21 \mathrm{MJ} / \mathrm{kg}$. Composition 3, with the highest plastic content and the lowest paper content, had the highest overall heating value of $\sim 30 \mathrm{MJ} / \mathrm{kg}$.

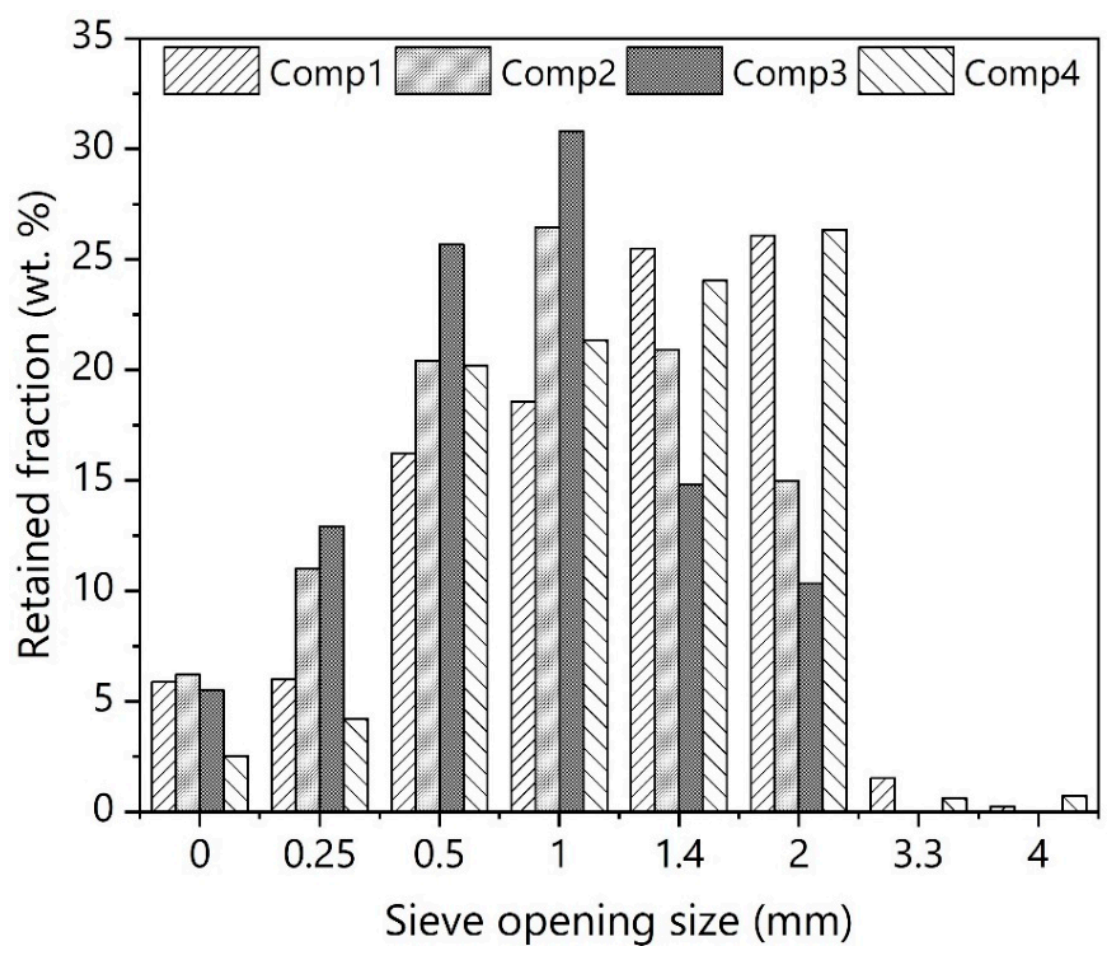

Figure 3. Particle size distribution of four ground RDF samples with four compositions listed in Table 1. The horizontal axis is the opening size of the screens used to sieve the compositions.

\subsection{RDF Compaction}

Figure 4 shows a typical force versus displacement curve for an RDF composition during compaction in the pellet die. The compaction increased until the applied force reached $5000 \mathrm{~N}$ at which compression stopped. During the first $80 \%$ of the compression cycle, particles only rearranged in the die and required a small amount of force. Rearrangement removed the void fraction of the bulk among the particles. For the last $20 \%$ of the compression cycle, the displacement was due to particle deformation. This stage contributed to forming dense pellets with an interlocked structure. The length of time for the particles to rearrange and to deform varied with composition. Paper made the rearrangement stage longer, plastic made it shorter.

Table 3 lists the densification ratio and density of the samples at the beginning and at the end of the compression stage with a die temperature of $80^{\circ} \mathrm{C}$. The densification ratio is calculated by dividing the volumes of the RDF inside the die over the volume of the RDF after compression. Densification ratio has a direct correlation with paper content. Compositions 1 and 4 , with $50 \%$ paper content, had the highest densification ratios of 10.6 and 10.2, respectively. Such high densification ratios resulted in denser pellets. Pellets produced from compositions 1 and 4 had densities of 1150 and $1200 \mathrm{~kg} / \mathrm{m}^{3}$, respectively. Reducing the paper content to $30 \%$ in composition 3 lowered the densification ratio to 6.5 . For this composition, the pellet density decreased to $1040 \mathrm{~kg} / \mathrm{m}^{3}$.

The steep rise of the required force in the deformation stage of the pelletization curve showed that the tested RDF samples were rigid and exhibited low deformation. For this type of material, after the full rearrangement of particles, a large force is required to make a small displacement. Analyzing the cumulative fraction of compression energy input at each level of displacement revealed that in the first $80 \%$ of displacement, only $5 \%$ of total energy was used. About $72 \%$ of the required compression energy was used during the last $5 \%$ of displacement. 


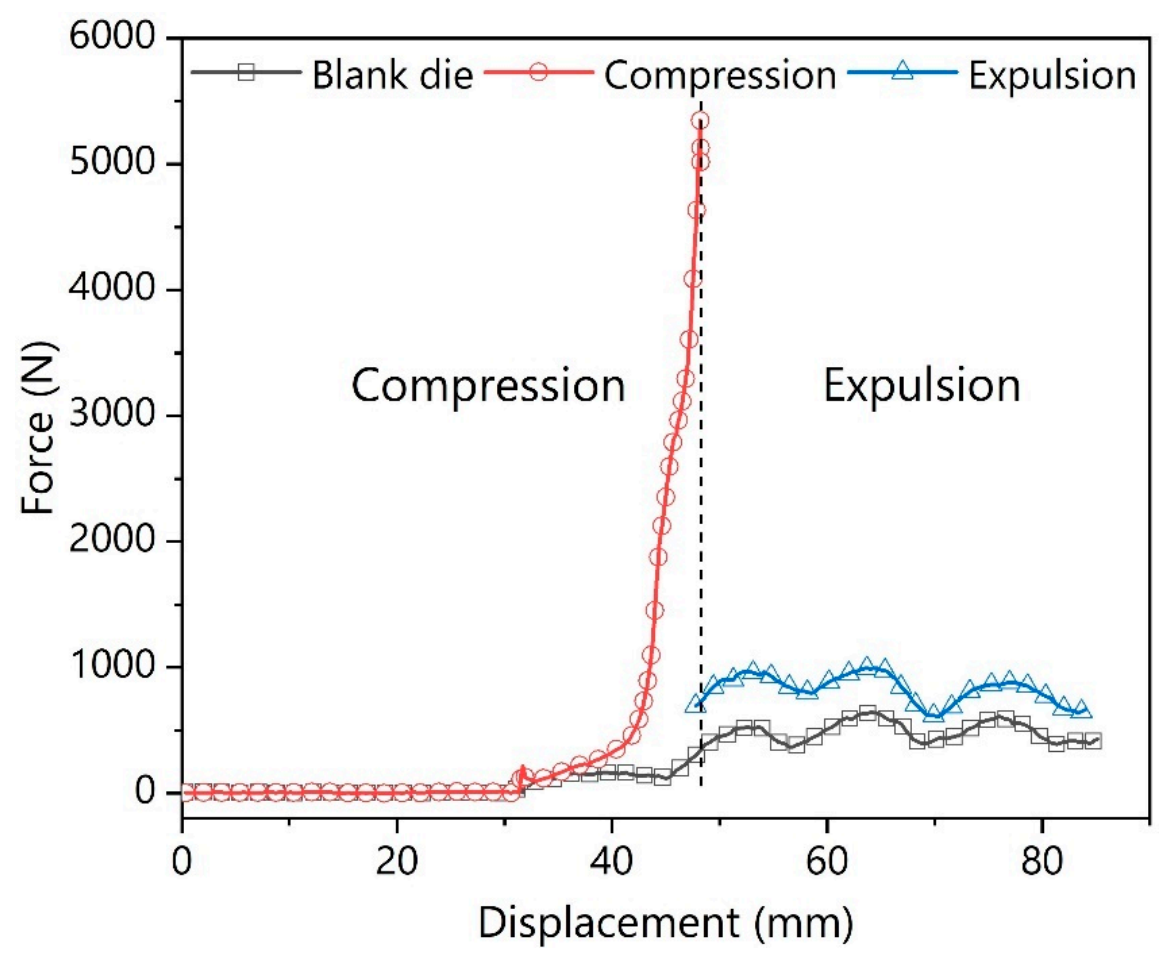

Figure 4. A sample force vs displacement graph of a single RDF pellet inside the die at $80^{\circ} \mathrm{C}$.

Figure 4 also shows the force versus displacement plot during the expulsion of the pellet from die. The applied force to push the pellet with a constant displacement rate shows a cyclic variation, probably due to cycling compression and relaxation inside the die. Blank test force measurement shows the friction in the empty die assembly. The measured force in the blank test was excluded from the pelletization force measured for each composition. The measured force in the expulsion stage represents the friction between the pellet's outer surface and the die's internal surface. The area beneath each part of the curve represents the required energy to complete each stage.

Figure 5 shows the energy input in each pelletization stage for four compositions. All compositions consumed a similar compression energy input, but the expulsion energy input varied with composition. Increasing the paper content from $30 \%$ in composition 3 to $50 \%$ in composition 1 required more energy. The paper contained cellulosic fibers, which caused large friction with the die internal surface compared to other fractions. Increasing the plastic content from $20 \%$ in composition 1 to $40 \%$ in composition 3 reduced the expulsion energy. Softened plastic particles inside the hot pellet die facilitated the expulsion of the material. Low paper content and high plastic content minimized the total energy requirement.

Paper content increased pellet durability (Table 4). As previously mentioned, the interlocking of the paper particles improved durability. Durability analysis showed that paper had a strong influence on strengthen the pellet structure. Compositions 1 and 4 had the highest paper content of $50 \%$ and their durability values were $\sim 92 \%$.

Table 4. Durability of the pellets with four compositions made at a die temperature of $80{ }^{\circ} \mathrm{C}$.

\begin{tabular}{ccccc}
\hline Sample & Comp 1 & Comp 2 & Comp 3 & Comp 4 \\
\hline Durability (\%) & $92.25 \pm 4.07$ & $66.06 \pm 6.05$ & $50.96 \pm 6.69$ & $92.38 \pm 4.74$ \\
\hline
\end{tabular}




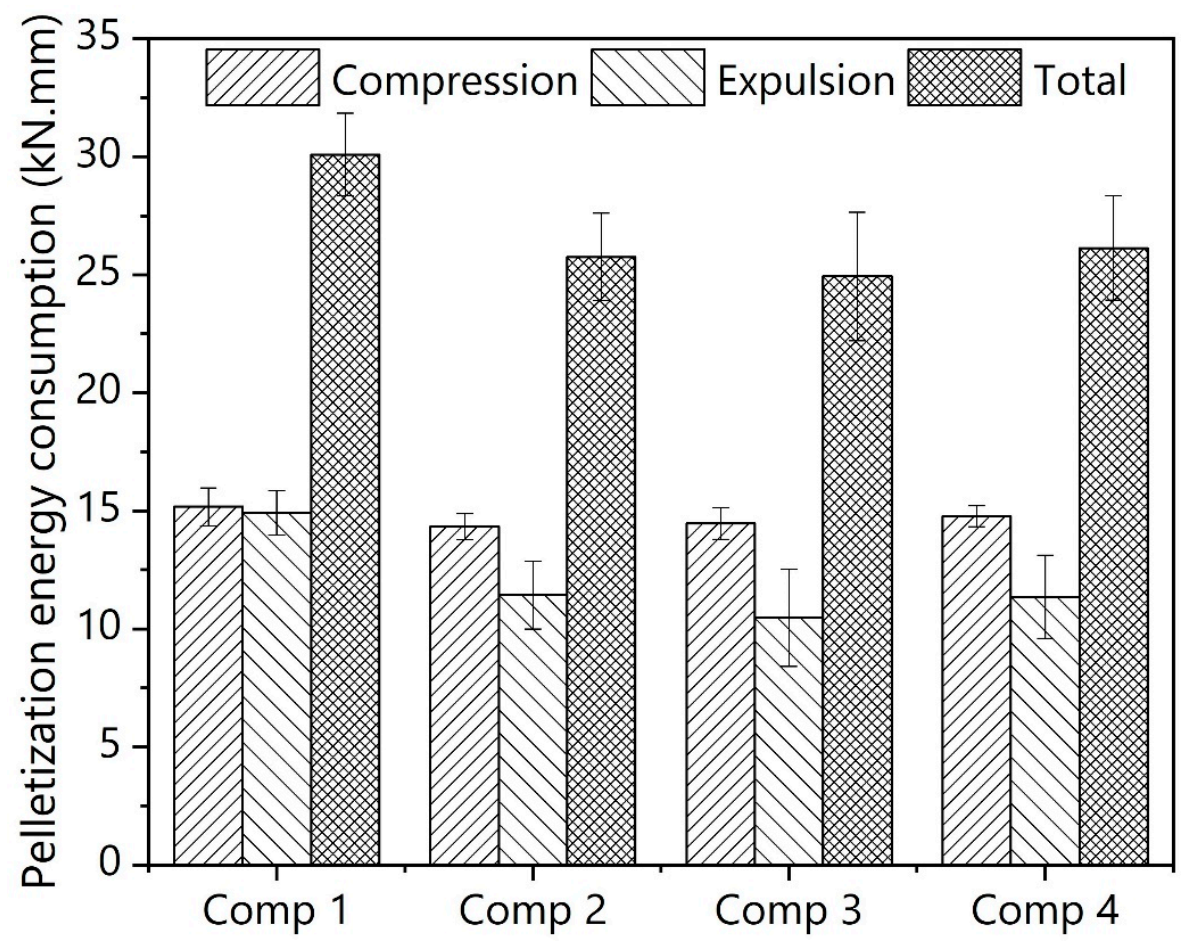

Figure 5. Pelletization energy input for four RDF compositions. Total energy input is the summation of compression and expulsion stages.

The plastic content was supposed to soften and act as a binder in the pellet structure, but this effect was not observed at $80{ }^{\circ} \mathrm{C}$. When plastic content increased to $40 \%$ in composition 3 , pellets were bent from the point with the maximum plastic accumulation (Figure 6). This means that $80{ }^{\circ} \mathrm{C}$ was not hot enough to melt the plastics through the pellet structure. The increase in plastic made pellets more fragile during the durability tests. Durability of composition 3 with $40 \%$ plastic and $30 \%$ paper content was $\sim 50 \%$, while the durability of composition 1 with $20 \%$ plastic and $50 \%$ paper was larger than $90 \%$.

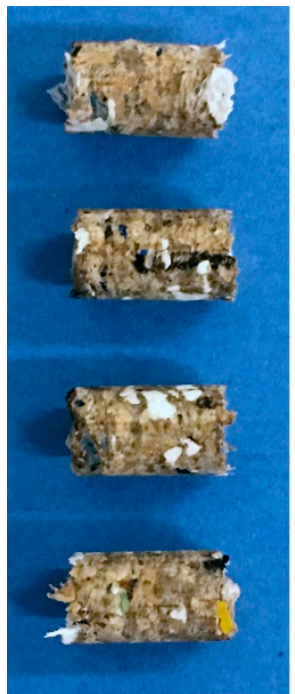

Comp 1

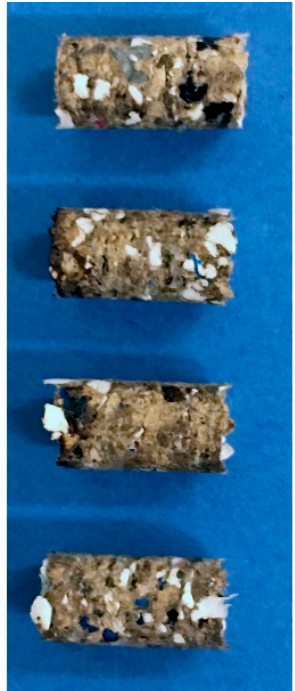

Comp 2

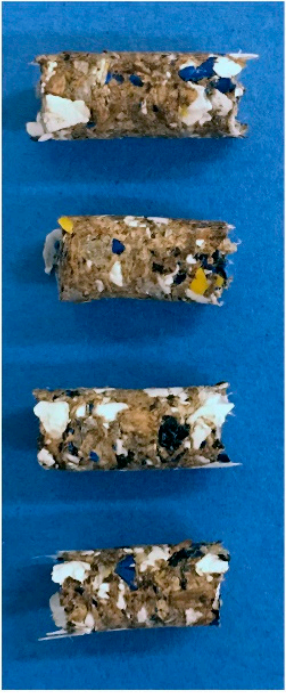

Comp 3

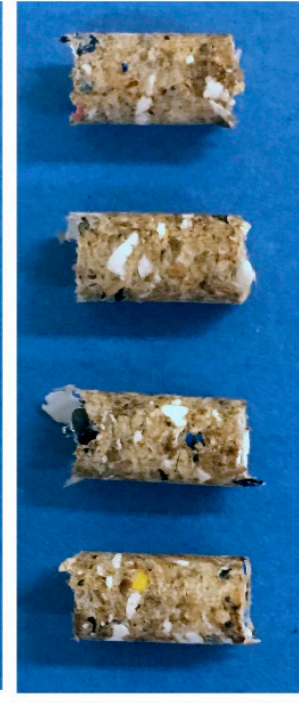

Comp 4

Figure 6. Picture of pellets produced from four different RDF compositions. The diameter of pellets was $\sim 6.4 \mathrm{~mm}$. 
The hypothesis was that sufficient heat should be provided to melt the plastic particles, especially the hard plastic to strengthen the pellet structure. As a follow-up, composition 3 was pelletized at $100{ }^{\circ} \mathrm{C}$ die temperature. The pellets did not bend and kept their shape during the 5-day storage period in an open environment. The durability of pellets increased from $51 \%$ at $80{ }^{\circ} \mathrm{C}$ to $94 \%$ at $100{ }^{\circ} \mathrm{C}$. Elevating the die temperature did not increase pelletization energy but reduced the variability of measurements. We concluded that the plastic content of $40 \%$ needed a temperature of at least $100{ }^{\circ} \mathrm{C}$ to produce durable pellets.

Analysis of variance (ANOVA) in Table 5 showed that plastic content had a larger impact than paper content on the energy consumption, while the paper content had a larger influence on pellet durability (compare the $F$-values). In hindsight, we should have had a larger sample size and variation in fractions in order to develop a full regression analysis. That analysis would have revealed a full interaction of the levels of the composition fractions in the blend.

Table 5. Analysis of variance (ANOVA) for the influence of plastic and paper content on pelletization energy consumption and pellet durability.

\begin{tabular}{cccccc}
\hline Source & DF & Adj SS $^{\mathbf{1}}$ & Adj MS $^{2}$ & F-Value & $p$-Value \\
\hline \multicolumn{5}{c}{ Pelletization energy consumption } \\
Regression & 2 & 13.7864 & 6.8932 & 3.38 & 0.359 \\
Plastic content (\%) & 1 & 6.2118 & 6.2118 & 3.04 & 0.331 \\
Paper content (\%) & 1 & 0.4736 & 0.4736 & 0.23 & 0.714 \\
Error & 1 & 2.0417 & 2.0417 & - & - \\
Total & 3 & 15.8281 & - & - & - \\
Regression equation & $40.2-0.337$ (Plastic content, \%) - 0.079 (Paper content, \%) \\
\hline \multicolumn{5}{c}{ Pellet durability } \\
\hline Regression & 2 & 1236.29 & 618.147 & 0.128 \\
Plastic content (\%) & 1 & 2.13 & 2.135 & 0.10 & 0.145 \\
Paper content (\%) & 1 & 383.86 & 383.861 & 18.73 & - \\
Error & 1 & 20.50 & 20.498 & - & - \\
Total & 3 & 1256.79 & - & - & \\
Regression equation & $-26.7+0.198$ (Plastic content, \%) + 2.262 (Paper content, \%) \\
\hline
\end{tabular}

${ }^{1}$ Adjusted sum of square. ${ }^{2}$ Adjusted mean squares

\section{Conclusions}

This research presented the pelletization of RDF samples made up of several proportions of paper, plastic and organic material. The fraction of wood in the sample did not vary. The experimental data confirmed that paper and plastic had opposite influences on pelletization performance. Higher paper content increased the total energy for compaction but generated a higher durable pellet. Higher plastic content lowered the pellet durability at $80^{\circ} \mathrm{C}$ but increased durability considerably at $100{ }^{\circ} \mathrm{C}$ pelletization temperature. The plastic fraction that was prepared in this study had the highest heating value of $46.5 \mathrm{MJ} / \mathrm{kg}$ and paper had the lowest heating value of $\sim 15 \mathrm{MJ} / \mathrm{kg}$. Composition 3 with the highest plastic and minimum paper content generated pellets with an overall heating value of $\sim 30 \mathrm{MJ} / \mathrm{kg}$. As the plastic content contributed to the higher calorific value, it is suggested to use high plastic content and operate at a temperature higher than plastic's softening point, that is, greater than $100{ }^{\circ} \mathrm{C}$.

Author Contributions: Conceptualization, H.R., S.S. and C.J.L.; methodology, H.R.; formal analysis, H.R.; resources, H.R. and F.Y.P.; data curation, H.R. and S.S.; writing-original draft preparation, H.R.; writing-review and editing, H.R., F.Y.P., C.J.L. and S.S.; visualization, H.R.; supervision, S.S.; project administration, H.R. and F.Y.P.; funding acquisition, S.S. All authors have read and agreed to the published version of the manuscript.

Funding: This research was funded by Mitacs Canada grant number of IT14044.

Conflicts of Interest: The authors declare no conflict of interest. 


\section{References}

1. Caputo, A.C.; Pelagagge, P.M. RDF production plants: II Economics and profitability. Appl. Therm. Eng. 2002, 22, 439-448. [CrossRef]

2. Sarc, R.; Lorber, K.E. Production, quality and quality assurance of Refuse Derived Fuels (RDFs). Waste Manag. 2013, 33, 1825-1834. [CrossRef] [PubMed]

3. Alter, H. The "Recycling" of Densified Refuse-Derived Fuel. Waste Manag. Res. 1996, 14, 311-317. [CrossRef]

4. Casado, R.R.; Rivera, J.A.; García, E.B.; Cuadrado, R.E.; Llorente, M.F.; Sevillano, R.B.; Delgado, A.P. Classification and characterisation of SRF produced from different flows of processed MSW in the Navarra region and its co-combustion performance with olive tree pruning residues. Waste Manag. 2016, 47, $206-216$. [CrossRef] [PubMed]

5. Grosso, M.; Dellavedova, S.; Rigamonti, L.; Scotti, S. Case study of an MBT plant producing SRF for cement kiln co-combustion, coupled with a bioreactor landfill for process residues. Waste Manag. 2016, 47, 267-275. [CrossRef]

6. Tanigaki, N.; Ishida, Y.; Osada, M. A case-study of landfill minimization and material recovery via waste co-gasification in a new waste management scheme. Waste Manag. 2015, 37, 137-146. [CrossRef]

7. Ayvaz-Cavdaroglu, N.; Coban, A.; Firtina-Ertis, I. Municipal solid waste management via mathematical modeling: A case study in İstanbul, Turkey. J. Environ. Manag. 2019, 244, 362-369. [CrossRef]

8. Chang, Y.-H.; Chen, W.C.; Chang, N.-B. Comparative evaluation of RDF and MSW incineration. J. Hazard. Mater. 1998, 58, 33-45. [CrossRef]

9. Rada, E.C. Present and future of SRF. Waste Manag. 2016, 47, 155-156. [CrossRef]

10. Caputo, A.C.; Pelagagge, P.M. RDF production plants: I Design and costs. Appl. Therm. Eng. 2002, 22, 423-437. [CrossRef]

11. Infiesta, L.R.; Ferreira, C.R.N.; Trovó, A.G.; Borges, V.L.; Carvalho, S.R. Design of an industrial solid waste processing line to produce refuse-derived fuel. J. Environ. Manag. 2019, 236, 715-719. [CrossRef] [PubMed]

12. Guo, Y.; Li, Y.; Lou, X.; Guan, J.; Li, Y.; Mai, X.; Liu, H.; Zhao, C.X.; Wang, N.; Yan, C.; et al. Improved extraction of cobalt and lithium by reductive acid from spent lithium-ion batteries via mechanical activation process. J. Mater. Sci. 2018, 53, 13790-13800. [CrossRef]

13. Tomasek, S.; Varga, Z.; Hancsók, J. Production of jet fuel from cracked fractions of waste polypropylene and polyethylene. Fuel Process. Technol. 2020, 197, 106197. [CrossRef]

14. Alter, H. The history of refuse-derived fuels. Resour. Conserv. 1987, 15, 251-275. [CrossRef]

15. Fyffe, J.R.; Breckel, A.C.; Townsend, A.K.; Webber, M.E. Use of MRF residue as alternative fuel in cement production. Waste Manag. 2016, 47, 276-284. [CrossRef]

16. Georgiopoulou, M.; Lyberatos, G. Life cycle assessment of the use of alternative fuels in cement kilns: A case study. J. Environ. Manag. 2018, 216, 224-234. [CrossRef]

17. Ko, A.S.; Chang, N.-B. Optimal planning of co-firing alternative fuels with coal in a power plant by grey nonlinear mixed integer programming model. J. Environ. Manag. 2008, 88, 11-27. [CrossRef]

18. Seljak, T.; Katrašnik, T. Designing the microturbine engine for waste-derived fuels. Waste Manag. 2016, 47, 299-310. [CrossRef]

19. Sever Akdağ, A.; Atımtay, A.; Sanin, F.D. Comparison of fuel value and combustion characteristics of two different RDF samples. Waste Manag. 2016, 47, 217-224. [CrossRef]

20. Dunnu, G.; Maier, J.; Schnell, U.; Scheffknecht, G. Drag coefficient of Solid Recovered Fuels (SRF). Fuel 2010, 89, 4053-4057. [CrossRef]

21. Soleimani, M.; Tabil, X.L.; Grewal, R.; Tabil, L.G. Carbohydrates as binders in biomass densification for biochemical and thermochemical processes. Fuel 2017, 193, 134-141. [CrossRef]

22. Rezaei, H. Physical and Thermal Characterization of Ground Wood Chip and Ground Wood Pellet Particles. Ph.D. Thesis, University of British Columbia (UBC), Vancouver, BC, Canada, 2017.

23. Larsson, S.H.; Lestander, T.A.; Crompton, D.; Melin, S.; Sokhansanj, S. Temperature patterns in large scale wood pellet silo storage. Appl. Energy 2012, 92, 322-327. [CrossRef]

24. Lam, P.S.; Sokhansanj, S.; Bi, X.T.; Lim, C.J.; Melin, S. Energy Input and Quality of Pellets Made from Steam-Exploded Douglas Fir (Pseudotsuga menziesii). Energy Fuels 2011, 25, 1521-1528. [CrossRef]

25. Lam, P.Y.; Lam, P.S.; Sokhansanj, S.; Bi, X.T.; Lim, C.J.; Melin, S. Effects of pelletization conditions on breaking strength and dimensional stability of Douglas fir pellet. Fuel 2014, 117, 1085-1092. [CrossRef] 
26. Brigagão, G.V.; de Queiroz Fernandes Araújo, O.; de Medeiros, J.L.; Mikulcic, H.; Duic, N. A techno-economic analysis of thermochemical pathways for corncob-to-energy: Fast pyrolysis to bio-oil, gasification to methanol and combustion to electricity. Fuel Process. Technol. 2019, 193, 102-113. [CrossRef]

27. Rajput, S.P.; Jadhav, S.V.; Thorat, B.N. Methods to improve properties of fuel pellets obtained from different biomass sources: Effect of biomass blends and binders. Fuel Process. Technol. 2020, 199, 106255. [CrossRef]

28. Sprenger, C.J.; Tabil, L.G.; Soleimani, M.; Agnew, J.; Harrison, A. Pelletization of Refuse-Derived Fuel Fluff to Produce High Quality Feedstock. J. Energy Resour. Technol. 2018, 140, 042003. [CrossRef]

29. Sprenger, C.; Tabil, L.G.; Soleimani, M. Compression and Relaxation Properties of Municipal Solid Waste Refuse-Derived Fuel Fluff. KONA Powder Part. J. 2018, 35, 200-208. [CrossRef]

30. Rezaei, H.; Yazdanpanah, F.; Lim, C.J.; Sokhansanj, S. Pelletization properties of refuse-derived fuel-Effects of particle size and moisture content. Fuel Process. Technol. 2020, 205, 106437. [CrossRef]

31. Bessi, C.; Lombardi, L.; Meoni, R.; Canovai, A.; Corti, A. Solid recovered fuel: An experiment on classification and potential applications. Waste Manag. 2016, 47, 184-194. [CrossRef]

32. EPA Municipal Solid Waste Generation, Recycling, and Disposal in the United States: Facts and Figures for 2012; United States Environmental Protection Agency: Washington, DC, USA, 2012.

33. Rezaei, H.; Sokhansanj, S. Physical and thermal characterization of ground bark and ground wood particles. Renew. Energy 2018, 129, 583-590. [CrossRef]

34. Rezaei, H.; Lim, J.; Sokhansanj, S. Comparison of Drying Rates of Ground Western Red Cedar with Hemlock, Birch, Aspen and Spruce/Pine/Douglas Fir. Appl. Eng. Agric. 2020, 36, 159-165. [CrossRef]

35. Nielsen, S.K.; Rezaei, H.; Mandø, M.; Sokhansanj, S. Constitutive modelling of compression and stress relaxation in pine pellets. Biomass Bioenergy 2019, 130, 105370. [CrossRef]

36. Schilling, C.; Wohler, M.; Yazdanpanah, F.; Bi, X.; Sokhansanj, S. Development of a Novel Wood Pellet Durability Tester for Small Samples Conference of World Sustainable Energy Days. In Proceedings of the World Sustainable Energy Days-Energy Efficiency \& Biomass, At Wels, Austria, 25-27 February 2015; The OÖ Energiesparverband: Wels, Austria, 2015. [CrossRef]

37. Chang, N.-B.; Chang, Y.-H.; Chen, W.C. Evaluation of heat value and its prediction for refuse-derived fuel. Sci. Total Environ. 1997, 197, 139-148. [CrossRef]

(C) 2020 by the authors. Licensee MDPI, Basel, Switzerland. This article is an open access article distributed under the terms and conditions of the Creative Commons Attribution (CC BY) license (http://creativecommons.org/licenses/by/4.0/). 